Editorial

\title{
Challenges of Organ Transplantation in COVID-19 Era
}

\author{
Kamal Kant Sahu*
}

Divisionof Hematology and Oncology, Department of Internal Medicine, Saint Vincent Hospital, Worcester, MA 01608, USA; E-Mail: drkksahu85@gmail.com

* Correspondence: Kamal Kant Sahu; E-Mail: drkksahu85@gmail.com

Academic Editor: Kamal Kant Sahu

Special Issue: COVID-19 and Organ Transplantation

OBM Transplantation

2020, volume 4, issue 4

doi:10.21926/obm.transplant.2004126
Received: November 01, 2020

Accepted: November 02, 2020

Published: November 19, 2020

COVID-19 pandemic has shattered world with its innumerable challenges. In addition to the saturation of the medical and health care facilities, physicians and patients are struggling to manage the chronic and acute health care issues in addition to COVID-19 [1].

Patients suffering from hematological and oncological malignancies are amongst the worst hit due to the interruption in the treatment of various cancers. Similarly, recipients of various solid organ transplants are at the mercy of fate due to COVID-19 surge. It takes enormous effort to find a right donor, ensure the eligibility of the recipients, and to manage the post-transplant complications [2]. However, during the COVID-19 pandemic, the challenges associated with every step for a successful transplantation has increased exponentially. The COVID-19 pandemic has led to reduction in organ donation and transplantation in various countries including the United States and other European countries [3, 4]. For instance, In Australia, the percentage of kidney transplantation has gone down by $27 \%$ as compared to 2019 [2].

Various oncologists and transplant physicians and surgeons are trying to gather as much information as possible based on individual and/or institutional experiences. There is a constant attempt to formulate interim guidelines by various medical societies to help physicians from different specialties [5-8].

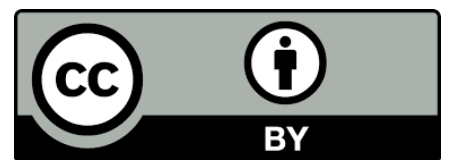

(C) 2020 by the author. This is an open access article distributed under the conditions of the Creative Commons by Attribution License, which permits unrestricted use, distribution, and reproduction in any medium or format, provided the original work is correctly cited. 
In addition to the drop in the number of donors, the concerns of recipients catching the COVID19 during peri-transplant period, use of immunosuppressive agents, follow up care also needs immediate attention. Other factors that is also impacting transplant services is the saturation and unavailability of the critical intensive care beds for the recipients in case they fall sick [9]. Similarly, other ancillaries like availability of blood transfusion products like red blood cell packets, platelets etc. are in scarcity due to decline in blood donation drives [10]. Staff, physician assistants, nurses, pathologists, radiologists, and many more are involved in the transplant team whose wellbeing and availability are essential to ensure a successful transplantation during this pandemic.

To conclude, we are in an incredibly challenging situation where a fine balance is required to diligently make decisions for our patients on transplant waitlist. Case to case basis decision making considering the factors like disease severity, risks and benefits involved in waiting vs proceeding with the transplant should be made for the best outcomes.

\section{Author Contributions}

Kamal Kant Sahu did all work.

\section{Competing Interests}

The author has declared that no competing interests exist.

\section{References}

1. Sahu KK, Siddiqui AD, Cerny J. Mesenchymal stem cells in COVID-19: A journey from bench to bedside. Lab Med. 2020; Imaa049.

2. Chadban SJ, McDonald M, Wyburn K, Opdam H, Barry L, Coates PT. Significant impact of COVID-19 on organ donation and transplantation in a low-prevalence country: Australia. Kidney Int. 2020.

3. Loupy A, Aubert O, Reese PP, Bastien O, Bayer F, Jacquelinet C. Organ procurement and transplantation during the COVID-19 pandemic. Lancet. 2020; 395: e95-e96.

4. Manara A, Mumford L, Callaghan C., Ravanan R, Gardiner D. Donation and transplantation activity in the UK during the COVID-19 lockdown. Lancet. 2020; 396: 465-466.

5. Home: COVID-19 Information. Available From: https://www.myast.org/covid-19-information.

6. Jindal V, Sahu KK, Gaikazian S, Siddiqui AD, Jaiyesimi I. Cancer treatment during COVID-19 pandemic. Med Oncol. 2020; 37: 58.

7. Home: American society for transplantation and cellular therapy. Available From: https://www.astct.org/home.

8. Kant S, Menez SP, Hanouneh M, Fine DM, Crews DC, Brennan DC, et al. The COVID-19 nephrology compendium: AKI, CKD, ESKD and transplantation. BMC Nephrol. 2020; 21: 449.

9. Bhatla A, Ryskina KL. Hospital and ICU patient volume per physician at peak of COVID pandemic: State-level estimates. Healthc (Amst). 2020; 8: 100489.

10. Sahu KK, Raturi M, Siddiqui AD, Cerny J. "Because every drop counts": Blood donation during the COVID-19 pandemic. Transfus Clin Biol. 2020; 27: 105-108. 


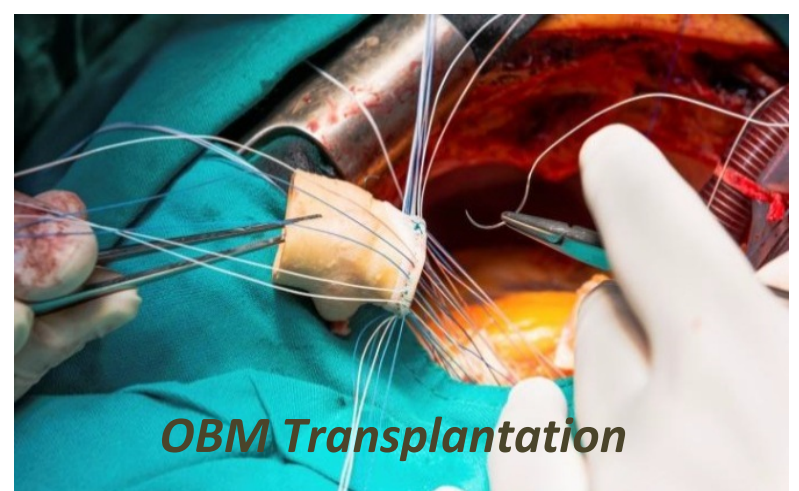

Enjoy OBM Transplantation by:

1. Submitting a manuscript

2. Joining in volunteer reviewer bank

3. Joining Editorial Board

4. Guest editing a special issue

For more details, please visit:

http://www.lidsen.com/journals/transplantation 